
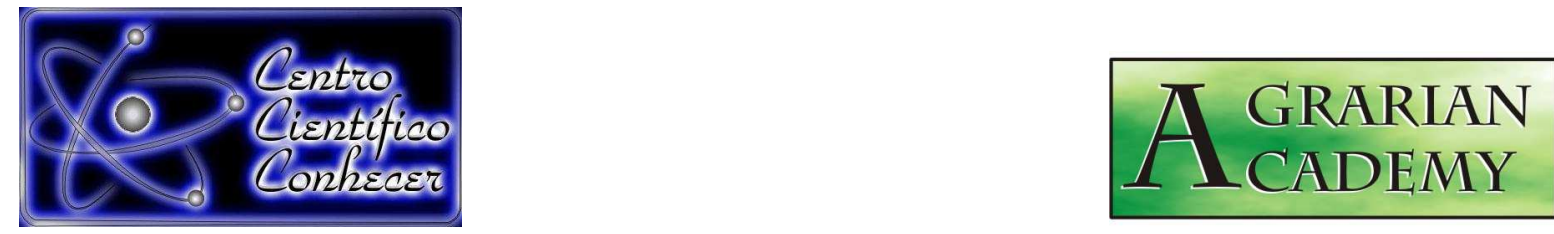

\title{
POTENCIAL GERMINATIVO DAS CULTIVARES DE AMENDOIM BR1 E BRS151L7 QUANTO AO TEMPO E MODO DE ARMAZENAMENTO
}

\section{Raquel Rodrigues Gonçalves ${ }^{1}$, Pedro Bruno Xavier de Alcantâra ${ }^{1}$; Brendo Alves da Silva Souza ${ }^{1}$; Laudeline Dantas Santana1; Felipe Thomaz da Camara². \\ 1- Graduando em Engenharia Agronômica, Bolsista do Programa de Educação Tutorial (PET) da Agronomia da Universidade Federal do Cariri (UFCA), Crato- CE, Brasil. raquel04rodrigues@hotmail.com; \\ 2- Professor Adjunto, Universidade Federal do Cariri (UFCA), Tutor do Pet Agronomia, Crato- CE.}

Recebido em: 30/11/2017 - Aprovado em: 15/12/2017 - Publicado em: 31/12/2017 DOI: 10.18677/Agrarian Academy 2017b20

\begin{abstract}
RESUMO
Este estudo teve por objetivo avaliar o potencial germinativo das cultivares BR1 e BRS151L7 quanto ao tempo e forma de armazenamento das sementes de amendoim. O experimento foi realizado no Centro de Ciências Agrárias e da Biodiversidade, na Universidade Federal do Cariri, Crato-CE. O ensaio foi do dia 10 de julho de 2017, 30 dias após a colheita do amendoim, e outro no dia 10 de agosto de 2017, 60 dias após a colheita do amendoim. O experimento foi realizado em delineamento inteiramente casualizado, em esquema fatorial $2 \times 2 \times 2$, com quatro repetições. O primeiro fator foi o tempo de armazenamento (30 e 60 dias), 0 segundo as cultivares (BR1 e BRS151L7) e o terceiro a forma de armazenamento das sementes (Grãos e Vagens). Foram avaliadas as seguintes variáveis: número de dias para iniciar e finalizar a emergência, emergência inicial e final, e o índice de velocidade de emergência. Ao analisar os resultados obtidos, conclui-se que as sementes de amendoim das cultivares BRS151L7 e BR1 apresentam características similares quanto ao tempo e modo de armazenamento, com o armazenamento em vagens sendo mais benéfico para a manutenção do poder germinativo do que 0 armazenamento direto dos grãos em garrafas Pet. As vagens não devem ser armazenadas por longos períodos, pois perdem consideravelmente seu poder germinativo.
\end{abstract}

PALAVRAS-CHAVE: Dias, emergência, grãos, vagem 


\title{
GERMINATION POTENTIAL OF PEANUT CULTIVARS BR 1 AND BRS 151 L7, REGARDING THE TIME AND MODE OF STORAGE.
}

\begin{abstract}
The objective of this study was to evaluate the germination potential of cultivars BR1 and BRS151L7 regarding the time and storage form of peanut seeds. The experiment was carried out at the Center of Agrarian Sciences and Biodiversity, at the Federal University of Cariri, Crato-CE. The trial was on July 10, 2017, 30 days after the peanut harvest, and another on August 10,2017, 60 days after the peanut harvest. The experiment was carried out in a completely randomized design, in a 2x2x2 factorial scheme, with four replications. The first factor was the storage time (30 and 60 days), the second the cultivars (BR1 and BRS151L7) and the third the storage form of the seeds (Grains and Pods). The following variables were evaluated: number of days to start and end the emergency, initial and final emergency, and the emergency speed index. In analyzing the results, it was concluded that the peanut seeds of the cultivars BRS151L7 and BR1 have similar characteristics regarding the time and mode of storage, with storage in pods being more beneficial for the maintenance of the germinative power than the direct storage of the seeds. Grains on Pet Bottles. The pods should not be stored for long periods, because they lose considerably their germinative power.
\end{abstract}

KEYWORDS: Pod; Grains; Emergency; Days.

\section{INTRODUÇÃO}

O amendoim (Arachis hypogaea. L) é uma das leguminosas mais consumidas pelos brasileiros, seja na forma in natura, torrado ou em algum derivado. Por essa razão, a busca constante por tecnologias que melhorem sua produção se faz necessária, visto que possui alto valor de mercado. O amendoim é considerado uma das mais importantes leguminosas, não só por sua expressão econômica, mas também por ser rico em proteínas e com valor energético de reconhecida qualidade. (GROTTA et al., 2008).

A maioria das cultivares presentes no mercado não são adaptadas para a região nordeste. Por essa razão a Empresa Brasileira de Pesquisa Agropecuária, desenvolveu duas cultivares de porte ereto com características endafoclimáticas para a região, sendo as cultivares BR1 (SANTOS et al., 2009) e BRS151L7 (VASCONCELOS et al., 2015). No nordeste, o amendoim é cultivado por pequenos produtores que acabam guardando os grãos colhidos de uma safra (sementes) para realizar o próximo cultivo, sendo armazenadas preferencialmente em vagens ou em grãos dentro de garrafas Pet (VASCONCELOS et al., 2015).

Estas formas de armazenamento, por sua vez, são cruciais, pois podem interferir no processo germinativo da cultura, que de acordo com Azeredo et al. (2005), sementes de amendoim armazenadas dentro dos frutos (vagens), apresentam vigor elevado durante os 12 primeiros meses, enquanto que sementes extraídas dos frutos (grãos) perdem acentuadamente o vigor após seis meses de armazenamento.

Esta redução na porcentagem de germinação interfere diretamente no stand final de plantas, que segundo Barbosa et al. (2014), esta redução na germinação das sementes é um problema constante para a obtenção de um stand adequado de plantas, reduzindo a produtividade das culturas. Para tanto, o presente trabalho objetivou avaliar a emergência das cultivares BR1 e BRS151L7 em função do tempo de armazenamento das sementes em vagem ou em grãos dentro de garrafas Pet. 


\section{MATERIAL E MÉTODOS}

O presente estudo foi realizado no Centro de Ciências Agrárias e da Biodiversidade (CCAB), na Universidade Federal do Cariri (UFCA), com altitude de $442 \mathrm{~m}$, e coordenadas geográficas de latitude sul $7^{\circ} 14^{\prime} 3,4^{\prime \prime}$ e longitude oeste $39^{\circ}$ 22 ' 7,6". Apresenta classificação climática Aw, de acordo com KÖeppen (ALVARES et al. 2013), sendo considerado clima tropical com inverno seco.

O experimento foi realizado no período de junho a agosto de 2017, em delineamento inteiramente casualizado, em esquema fatorial $2 \times 2 \times 2$, com quatro repetições. O primeiro fator foi o tempo de armazenamento (30 e 60 dias), o segundo as cultivares (BR1 e BRS151L7) e o terceiro a forma de armazenamento das sementes (Grãos e Vagens). A semeadura foi realizada em bandejas de isopor com 128 células, que foram preenchidas com substrato contendo metade de composto orgânico e metade de solo local, classificado como Argissolo Vermelho Amarelo, segundo a classificação de média intensidade do mapa de solos da FUNCEME (2012).

As sementes utilizadas foram colhidas no dia 10 de junho de 2017, sendo armazenadas em vagens ou em grãos dentro de garrafas Pet. Realizou-se um ensaio no dia 10 de julho de 2017, 30 dias após a colheita das vagens, e outro no dia 10 de agosto de 2017, 60 dias após a colheita das vagens. As sementes foram semeadas com profundidade de $1,0 \mathrm{~cm}$ e receberam irrigação diariamente.

Cada parcela experimental constava de 24 sementes, oriundas de vagens ou dos grãos que estavam armazenados nas garrafas Pet, de acordo com cada tratamento. As variáveis analisadas foram o número de dias necessários para iniciar e finalizar a emergência, sendo obtidos de forma visual, com o dia em que foi verificada a primeira plântula emergida sendo considerado o dia em que iniciou a emergência, e o último dia no qual se verificou a emergência das plântulas sendo o dia em que finalizou a emergência.

Para a análise das porcentagens de emergência inicial, considerou-se a porcentagem de plântulas emergidas aos sete dias após a semeadura, enquanto que a porcentagem de emergência final foi determinada após a última plântula emergir.

O índice de velocidade de emergência (IVE) foi calculado pela equação: IVE = $\mathrm{N} 1 / 1+\mathrm{N} 2 / 2+\mathrm{Nn} / \mathrm{n}$, em que $\mathrm{N}$ é o número de plântulas emergidas do primeiro até o dia $\mathrm{n}$ (última avaliação) e o denominador é o dia da análise. Os resultados obtidos foram submetidos à análise de variância e, havendo diferenças significativas, as médias foram comparadas pelo teste de Tukey a 5\% de probabilidade. As análises estatísticas foram realizadas no programa estatístico Sisvar 5.3.

\section{RESULTADOS E DISCUSSÃO}

$\mathrm{Na}$ Tabela 1 pode ser observado: a existência de interação significativa a 1\% de probabilidade entre os fatores tempo de armazenamento e cultivar em relação ao número de dias para iniciar a emergência (NDI), com o desdobramento da interação sendo apresentado na Tabela 2. Notou-se, ainda, que a forma de armazenamento não influenciou no NDI, com o armazenamento em grãos ou na vagem iniciando a emergência próximo a cinco dias após a semeadura. 
TABELA 1. Síntese da análise de variância e do teste de médias para o número de dias para iniciar a emergência (NDI), o número de dias para finalizar a emergência (NDF), a emergência inicial (EI), emergência final (EF) e o índice de velocidade de emergência (IVE).

$\begin{array}{llllll} & \text { NDI } & \text { NDF } & \text { EI } & \text { EF } & \text { IVE } \\ \text { Fatores } & \text { dias } & \text { dias } & \% & \% & \end{array}$

Tempo de

Armazenamento ( $\mathrm{T})$

30 dias

4,6

8,9 a

42,2

83,2

6,73

60 dias

5,1

$7,2 \mathrm{~b}$

37,5

39,8

5,53

Cultivar (C)

BRS151L7

4,5

8,0

$40,2 \mathrm{a}$

$60,5 \mathrm{a}$

$6,53 \mathrm{a}$

BR 1

5,2

8,1

$39,5 \mathrm{a}$

$62,5 \mathrm{a}$

$5,76 \mathrm{a}$

Armazenamento (A)

\begin{tabular}{cccccc} 
Grãos & 4,8 a & 7,9 & 34,4 & 52,3 & 5,09 \\
Vagens & $4,9 \mathrm{a}$ & 8,3 & 45,3 & 70,7 & 7,21 \\
\hline TESTE F & & & & & \\
T & $21,0^{* *}$ & $20,2^{* *}$ & $0,63^{\mathrm{NS}}$ & $129,7^{* *}$ & $3,91^{\mathrm{NS}}$ \\
$\mathbf{C}$ & $51,8^{* *}$ & $0,10^{\mathrm{NS}}$ & $0,02^{\mathrm{NS}}$ & $0,26^{\mathrm{NS}}$ & $1,68^{\mathrm{NS}}$ \\
$\mathbf{A}$ & $0,42^{\mathrm{NS}}$ & $0,93^{\mathrm{NS}}$ & $3,42^{\mathrm{NS}}$ & $23,2^{* *}$ & $12,9^{* *}$ \\
$\mathbf{T}^{\star} \mathbf{C}$ & $34,7^{* *}$ & $0,00^{\mathrm{NS}}$ & $0,02^{\mathrm{NS}}$ & $0,26^{\mathrm{NS}}$ & $0,00^{\mathrm{NS}}$ \\
$\mathbf{T}^{\star} \mathbf{A}$ & $3,85^{\mathrm{NS}}$ & $0,41^{\mathrm{NS}}$ & $5,67^{*}$ & $6,57^{*}$ & $8,9^{* *}$ \\
$\mathbf{C}^{*} \mathbf{A}$ & $0,42^{\mathrm{NS}}$ & $5,06^{*}$ & $0,15^{\mathrm{NS}}$ & $0,26^{\mathrm{NS}}$ & $0,00^{\mathrm{NS}}$ \\
$\mathbf{T}^{*} \mathbf{C}^{\star} \mathbf{A}$ & $3,85^{\mathrm{NS}}$ & $3,72^{\mathrm{NS}}$ & $0,43^{\mathrm{NS}}$ & $3,04^{\mathrm{NS}}$ & $1,13^{\mathrm{NS}}$ \\
\hline $\mathbf{C V} \%$ & 5,57 & 13,63 & 41,93 & 17,51 & 27,16
\end{tabular}

Médias seguidas pela mesma letra minúscula na coluna, não diferem entre si pelo teste de Tukey a $5 \%$ de probabilidade.

**: significativo $(\mathrm{P}<0,01)$; *: significativo $(\mathrm{P}<0,05)$; NS: não significativo; CV\%: coeficiente de variação.

$\mathrm{Na}$ tabela 2, observa-se que a cultivar BR1 começou a emergir antes da cultivar BRS151L7, quando armazenado por 30 dias, já com o armazenamento por 60 dias não houve diferença significativa. Quando observada a cultivar BR1, comparando os períodos de 30 e 60 dias de armazenamento, notou-se que o NDI foi semelhante. Já para a cultivar BRS151L7, verifica-se maior NDI no período de 60 dias de armazenamento. Esses resultados de rápido início da emergência podem ser atribuídos à alta qualidade fisiológica das sementes, que segundo Barbosa et al. (2014), deve-se ao fato das sementes provenientes das etapas de arranquio até 
quatro meses de armazenamento ainda apresentam elevados níveis de qualidade fisiológica.

TABELA 2. Desdobramento da Interação entre os fatores tempo de armazenamento e cultivar de amendoim para o número de dias para iniciar a emergência (NDI).

\begin{tabular}{ccc}
\hline Tempo de & \multicolumn{2}{c}{ Cultivar de Amendoim } \\
\cline { 2 - 3 } armazenamento (dias) & BR1 & BRS151L7 \\
\hline 30 & $5,3 \mathrm{aA}$ & $4,0 \mathrm{bB}$ \\
60 & $5,1 \mathrm{aA}$ & $5,0 \mathrm{aA}$
\end{tabular}

Médias seguidas pela mesma letra minúscula nas colunas e maiúscula nas linhas, não diferem entre si pelo teste de Tukey a $5 \%$ de probabilidade.

Para o número de dias para finalizar a emergência (Tabela 1), notou-se que os fatores cultivar e forma de armazenamento apresentaram interação significativa, com tal interação sendo desdobrada na Tabela 3. Para o tempo de armazenamento ocorreram diferenças significativas $(p<0,01)$, com as sementes que estavam armazenadas por 30 dias apresentando maior número de dias para finalizar a emergência do que as por 60 dias, função da melhor qualidade das sementes que permaneceram viáveis por maior período no solo.

De acordo com a tabela 3, a cultivar BR1 não sofreu influência da forma de armazenamento sobre o NDF, enquanto a cultivar BRS151L7 obteve menor tempo de emergência quando armazenado em grãos, finalizando o processo de germinação e emergência mais rápido. Comparando as cultivares em cada forma de armazenamento, em grãos ou em vagens, ambas cultivares não diferiram quanto ao NDF. Estes resultados contrastam com os de Barbosa et al. (2014) que verificaram que o processo de armazenamento afeta a qualidade e germinação das sementes.

TABELA 3. Desdobramento da Interação entre os fatores cultivar e forma de armazenamento de amendoim para o número de dias para finalizar a emergência (NDF).

\begin{tabular}{cll}
\hline \multirow{2}{*}{ Cultivar de Amendoim } & \multicolumn{2}{c}{ Forma de armazenamento } \\
\hline BR1 & Grãos & Vagem \\
\hline BRS151L7 & $8,4 \mathrm{aA}$ & $7,9 \mathrm{aA}$ \\
& $7,4 \mathrm{aB}$ & $8,6 \mathrm{aA}$
\end{tabular}

Médias seguidas pela mesma letra minúscula nas colunas e maiúscula nas linhas, não diferem entre si pelo teste de Tukey a $5 \%$ de probabilidade.

Quanto a porcentagem de emergência inicial, final e o IVE (Tabela 1), observou-se que ocorreu interação significativa entre os fatores tempo de armazenamento e forma de armazenamento, diferente do encontrado por Medeiros et al. (2013), que avaliando sementes de amendoim forrageiro, não verificaram ocorrência de interações significativas entre os fatores tempo e formas de armazenamento. Notou-se, também, que as cultivares obtiveram valores similares de EI, EF e IVE, com valores médios de 39,9\%, 61,5\% e 6,13, respectivamente (Tabela 1).

Como pode ser visto na tabela 4, quanto ao tempo e forma de armazenamento, o pior resultado de emergência inicial foi obtido para o armazenamento em grãos por 60 dias. Notou-se que se os grãos forem 
armazenados em grãos, por até 30 dias, a emergência inicial não será prejudicada, já o armazenamento em vagens não apresentou influência quanto aos dias de armazenamento. Diniz et al. (2012) obtiveram resultados semelhantes, em que o tempo de armazenamento diminuiu a frequência de germinação e vigor das sementes, sendo consideradas inadequadas para a semeadura segundo os autores.

TABELA 4. Desdobramento da Interação entre os fatores tempo e forma de armazenamento para a porcentagem de emergência inicial (\%).

\begin{tabular}{ccc}
\hline Tempo de & \multicolumn{2}{c}{ Forma de Armazenamento } \\
\cline { 2 - 3 } armazenamento (dias) & Grãos & Vagem \\
\hline 30 & $43,8 \mathrm{aA}$ & $40,6 \mathrm{aA}$ \\
60 & $25,0 \mathrm{bB}$ & $50,0 \mathrm{aA}$
\end{tabular}

Médias seguidas pela mesma letra minúscula nas colunas e maiúscula nas linhas, não diferem entre si pelo teste de Tukey a $5 \%$ de probabilidade.

Com relação à porcentagem de emergência final, na tabela 5, notou-se que tanto o armazenamento em grãos quanto em vagens tiveram resultados inferiores com 60 dias de armazenamento do que com 30 dias armazenados, sendo que em grãos apresentou o pior resultado. Herbes (2016) afirma que a velocidade e intensidade dos grãos ao perderem o poder germinativo estão diretamente interligadas a diversos fatores relacionados ao período de armazenamento, como guardar em locais inapropriados e com baixa umidade.

TABELA 5. Desdobramento da Interação entre os fatores tempo e forma de armazenamento para a porcentagem de emergência final (\%).

Tempo de

Forma de Armazenamento

\begin{tabular}{ccc} 
armazenamento (dias) & Grãos & Vagem \\
\cline { 2 - 3 } 30 & $78,9 \mathrm{aA}$ & $87,5 \mathrm{aA}$ \\
60 & $25,8 \mathrm{bB}$ & $53,9 \mathrm{bA}$
\end{tabular}

Médias seguidas pela mesma letra minúscula nas colunas e maiúscula nas linhas, não diferem entre si pelo teste de Tukey a $5 \%$ de probabilidade.

Na tabela 6 esta descrito o índice de velocidade de emergência em função da forma e tempo de armazenamento, com 30 dias não houve diferença entre as formas de armazenamento. Já com 60 dias, os grãos provenientes de armazenamento em vagens obtiveram melhor resultado quando comparados ao armazenamento em grãos. Barbosa et al. (2014) relatam em trabalho semelhante que a forma de armazenamento das sementes de amendoim afeta a velocidade de emergência, corroborando com os resultados desta pesquisa, bem como Santos et al. (2013), que verificaram que as sementes armazenadas nas vagens não apresentaram perdas de germinação, enquanto aquelas que foram beneficiadas perderam vigor e poder germinativo.

TABELA 6. Desdobramento da Interação entre os fatores tempo e forma de armazenamento para índice de velocidade de emergência.

\begin{tabular}{ccc}
\hline Tempo de & \multicolumn{2}{c}{ Forma de Armazenamento } \\
\cline { 2 - 3 } armazenamento (dias) & Grãos & Vagem \\
\hline 30 & $6,55 \mathrm{aA}$ & $6,91 \mathrm{aA}$ \\
60 & $3,62 \mathrm{bB}$ & $7,51 \mathrm{aA}$ \\
\hline
\end{tabular}

Médias seguidas pela mesma letra minúscula nas colunas e maiúscula nas linhas, não diferem entre si pelo teste de Tukey a $5 \%$ de probabilidade.

AGRARIAN ACADEMY, Centro Científico Conhecer - Goiânia, v.4, n.8; p. 199 


\section{CONCLUSÃO}

O presente trabalho permitiu concluir que as sementes de amendoim das cultivares BRS151L7 e BR1 apresentam características de emergência similares quanto ao tempo e forma de armazenamento.

$O$ armazenamento em vagens mostrou-se mais benéfico para a manutenção do poder germinativo do que em grãos, sendo mais recomendável para os produtores que desejam armazenar suas sementes.

As vagens não devem ser armazenadas por longos períodos, pois perdem consideravelmente o poder germinativo.

\section{AGRADECIMENTOS}

À Universidade Federal do Cariri (UFCA) pela concessão de bolsas de estudo por meio do Programa de Educação Tutorial (Pet) da Agronomia, que possibilitaram a execução desta pesquisa.

\section{REFERÊNCIAS}

ALVARES, C. A.; STAPE, J. L.; SENTELHAS, P. C.; GONÇALVES, J. L. M.; SPAROVEK, G. Koöppen's climate classification map for Brazil. Meteorologische Zeitschrift, Berlim, v. 22, n. 6, p. 711-728, 2013.

AZEREDO, G. A. A; BRUNO, R. L. A; LOPES, K. P; SILVA, A; DINIZ, E; LIMA, A.A. Conservação de sementes de amendoim (arachis hypogaea l.) em função do beneficiamento, embalagem e ambiente de armazenamento. Pesquisa Agropecuária Tropical, v.35, n.1, p. 37-44, 2005. Disponível em: < https://www.revistas.ufg.br/pat/article/view/2284>. Acesso em 17 de Nov. 2017. DOI: https://doi.org/10.5216/pat.v35i1.2284

BARBOSA, R. M; VIEIRA, B. G. T. L; MARTINS, C.C; VIEIRA, R.D. Qualidade fisiológica e sanitária de sementes de amendoim durante o processo de produção. Pesquisa Agropecuária Brasileira, Brasília, v.49, n.12, p.977-985, 2014. Disponível em:< http://www.scielo.br/pdf/pab/v49n12/0100-204X-pab-49-12-00977.pdf>, Acesso em 17 de Nov. 2017. DOI: 10.1590/S0100-204X2014001200008.

DINIZ, R.S.; SÁ, M.E. de; ABRANTES, F.L.; SOUZA, L.C.D. de; DAIUTO, E.R. Qualidade de sementes em função do tempo de armazenamento em amendoim. Revista Iberoamericana de Tecnología Postcosecha, v.13, p.86-91, 2012. Disponível em: <http://www.uacm.kirj.redalyc.redalyc.org/articulo.oa?id=81324433011> ISSN 16650204. Acesso em 17 de Nov. 2017.

FUNCEME. Levantamento de reconhecimento de média intensidade dos solos da Mesoregião do Sul Cearense / Fundação Cearense de Meteorologia e Recursos Hídricos. Fortaleza, 2012.

GROTTA, D. C. C; FURLANI, C. E. A; SILVA, R. P; REIS, G. N; CORTEZ, J.W; ALVES, P. J. Influência da profundidade de semeadura e da compactação do solo sobre a semente na produtividade do amendoim. Ciência e Agrotecnologia, Lavras, v.32, n.2 , p. 547-552, 2008. Disponível em< http://dx.doi.org/10.1590/S1413- 
$70542008000200031>$. Acesso em 17 de Nov. de 2017. DOI 10.1590/S141370542008000200031

HERBES, M. G. Como armazenar sementes na propriedade?. 2016, Disponível em: < http://www.pioneersementes.com.br/blog/113/como-armazenar-sementes-napropriedade >. Acesso em 17de Nov. de 2017.

MEDEIROS, L. T.; SALES, J. F.; SOUZA, R. G.; ALVES, B. A.; FREITAS, N. F. Qualidade fisiológica de sementes de amendoim forrageiro submetidas a diferentes tempos e ambientes de armazenamento. Revista Brasileira de Saúde e Produção Animal, Salvador, v.14, n.3, p.472-477, 2013. Disponível em< http://www.scielo.br/pdf/rbspa/v14n3/06.pdf>. Acesso em 17 de Nov. de 2017. DOI: doi.org/10.1590/S1519-99402013000300006.

SANTOS, F.; MEDINA, P. F.; LOURENÇÃO, A. L.; PARISI, J. J. D.; GODOY, I. J. Qualidade de sementes de amendoim armazenadas no estado de São Paulo. Bragantia, Campinas, v. 72, n. 3, p.310-317, 2013. Disponível em < http://www.scielo.br/scielo.php?script=sci_arttext\&pid=S0006-

7052013000300014\&Ing=pt\&tlng=pt>. Acesso em 17 de Nov. de 2017 DOI: doi.org/10.1590/brag.2013.029

SANTOS, R. C. dos; MOREIRA, J. de A. N.; VALLE, L. V.; FREIRE, R. M. M.; ALMEIDA, R. P. de; ARAÚJO, J. M.; SILVA, L. C. Cultivar de amendoim BR 1. Embrapa Algodão. 2009. Disponível em:< https://ainfo.cnptia.embrapa.br/digital/bitstream/item/25513/1/FolderAmendoimBR14ed.pdf >. Acesso em 17 de Nov. de 2017.

VASCONCELOS, F. M. T. de; VASCONCELOS, R. A. de; LUZ, L. N. da; CABRAL, N. T.; OLIVEIRA JÚNIOR, J. O. L. de; SANTIAGO, A. D.; SAGRILO, E.; FARIAS, F. J. C.; MELO FILHO, P. de A.; SANTOS, R. C. dos. Adaptabilidade e estabilidade de genótipos eretos de amendoim cultivados nas regiões Nordeste e Centro-Oeste. Ciência Rural, Santa Maria, v.45, n.8, p.1375-1380, ago, 2015. Disponivel em:< http://www.scielo.br/scielo.php?script=sci_arttext\&pid=S0103-

84782015000801375\&lng=pt\&tlng=pt > Acesso em 17 de Nov. de 2017. DOI: ttp://dx.doi.org/10.1590/0103-8478cr20140414 